\title{
Natural Hormones in Food-Producing Animals: Legal Measurements and Analytical Implications
}

\author{
Patricia Regal, Alberto Cepeda and Cristina A. Fente \\ University of Santiago de Compostela, \\ Spain
}

\section{Introduction}

Hormones are chemicals that are naturally produced in the body of animals and human beings and have a number of important functions in life, such as reproduction or growth. They act as messengers through the different parts of the organism and trigger and modulate key reactions to support and promote life. However, and due to the important role of these chemicals in several body functions, they also have been exogenously applied to animals and humans in order to obtain some kind of benefit in health or even to improve physical and growth performance. Focusing on the veterinary field, the most desirable action of hormones has always been reducing costs and obtaining more products of animal origin in shorter productive times, increasing the benefit per unit head for farmers. As a matter of fact, anabolic steroid hormones have played a key role among veterinary products in farming history and they have been one the most used and controversial components among veterinary drugs.

Usually, hormones work in harmony in the body and this status must be maintained to avoid metabolic disequilibrium and the subsequent illness. Besides, it has been reported the influence of exogenous steroids (presence in the environment and food products) in the development of several important illness in humans. With regard to food safety when treating animals with exogenous hormones, consumers' concerns have led to a complete prohibition of the use of substances having a hormonal action in food producing animals in the EU. Even when several regulations and laws exist all over the world with regard to the use of natural and synthetic hormones in animal husbandry, natural hormones have arisen as a real weak point of residue monitoring plans due to their natural origin. The existence of high variability through animals in terms of natural hormonal levels has been reported. This latest fact makes almost impossible to establish legal thresholds to control any exogenous administration of natural hormones to animals. That is why no final legal solution has been found yet to control the misuse and abuse of natural hormones exogenously applied to farm animals, even though a number of promising analytical procedures have already been published.

\section{Anabolic steroid hormones}

Throughout history, a large number of natural and synthetic substances have been applied in stock farming to speed up and improve animal growth, and to decrease feed costs. 
Anabolic agents or growth promoters are metabolic modifiers which improve efficiency and profitability of livestock production and improve carcass composition (Dikeman, 2007). Main physiologic effects of anabolic steroids include growth of muscle mass and strength, increased bone density, maturation of the sex organs, particularly important in the fetus, and at puberty the appearance of the secondary sex characteristics. The group of anabolic growth promotants includes compounds that naturally occur in an animal's body and synthetic chemicals that mimic the action of naturally occurring compounds. Meat industry have widely used anabolic hormones to quickly get larger quantities of meat and decrease inputs, reducing production costs, but also because they lead to a leaner carcass more in accordance to current consumer's preferences. Additionally, the zootechnical use of some sex hormones, such as estradiol or its esters (i.e., estradiol benzoate), which successfully regulate oestrus in cattle, has also led to important improvements and financial gain in stock farming (Cavalieri et al., 2005; Martínez et al., 2002).

Several illegal hormones have been used in the European Union (EU), as it has been reported in a series of European International Symposia and Conferences, such as EuroResidue Conferences on Residues of Veterinary Drugs in Food (Federation of European Chemical Societies, Division of Food Chemistry) and the Ghent Symposia on Hormone and Veterinary Drug Residue Analysis, amongst others. The number of active compounds is wide and continuously changing, as observed by the EU National Reference Laboratories (NRLs). Estrogenic, gestagenic and androgenic compounds (EGAs), as well as thyreostatic, corticosterois and $\beta$-agonist compounds, are also used alone or in growth promoting "cocktails" with low concentrations of several ones, that makes even more difficult their detection. There have been several European regulations regarding the use of EGAs as animal growth promoters because of their possible toxic effect on public health. In the Council Directive 96/22/EC (EC, 1996a) the EU prohibited the administration of substances having thyreostatic, oestrogenic, androgenic or gestagenic effects and of beta agonists in animal husbandry, while certain therapeutic applications of these drugs were still allowed. These anabolic steroids are included in group A substances according to Annex I of Directive 96/23/EC (EC, 1996b), which pertains to growth-promoting agents abused in animal fattening and unauthorized substances with no maximum residue limit (MRL). A zero-tolerance policy has been adopted, and especial analytical requirements have been stated in regard to these hormones (EC, 2002; European Commission, Directorate General for Health \& Consumers, 2004). However, the possibility of widespread abuse of hormonal substances by unscrupulous farmers and veterinary professionals in some parts of Europe still exists, mainly due to the economic benefits these substances provide in animal husbandry. On the other hand, the use of hormones to promote growth is still a legal practice in some parts of the world, which facilitates the existence of a possible "black market" of substances from these areas.

\subsection{Estrogenic drugs}

Cattle are the main food-producing species in which estradiol products are used for therapy or growth promotion. Estradiol benzoate, one of the most applied steroids in animal husbandry, was authorized for the treatment of pyometra and endometritis, for dilation of the cervix in cases of abortion, to enhance the expression of estrous behaviour, and to provoke luteolysis incorporated into estrous synchronization drug devices (i.e. PRID, 
CIDR), among other applications (Levy, 2010). In meat industry, it has been already reported that estrogenic implants (alone or in combination) increase carcass weight and longissimus muscle area and decrease intramuscular fat, compared with non-implanted steers (Boles et al., 2009; McPhee et al., 2006; Parr et al., 2011). Estrogenic implants also decrease kidney, pelvic and heart fat but apparently this fat increases for combination implants (McPhee et al., 2006). Cattle repeatedly treated with estradiol and trenbolone acetate implants have greater average daily gain and final weights than single-treated or non-treated steers, as well as more mature skeletons and higher protein content in their carcasses (Scheffler et al., 2003). However, hormonal treatments may have a negative effect on tenderness and meat quality of beef because they reduce marbling and advance skeletal or lean maturity (Dikeman, 2007; Hunter, 2010; Scheffler et al., 2003), this effect being more pronounced with combination implants than with estradiol alone. Beef flavour, juiciness and tenderness might be affected by trenbolone acetate implants but apparently this effect decreases with aging time (Igo et al., 2011).

On the other hand, the economic profitability of a dairy farm is based on the calving interval of the cows, in order to keep them as long as possible into lactating phase. To achieve this, the cow needs to get pregnant very quickly during postpartum, so the main step is the determination of the optimal time for insemination, basing on estrous behaviour. The expression of estrous behaviour is at a low level in modern dairy cows, resulting in low detection rates and longer calving intervals (Senger, 1994). Estradiol-based drugs, particularly those combined with progestins, appeared as a really effective and efficient solution to estrus detection problems in farm animals, allowing artificial insemination synchronization and high pregnancy rates to fixed-time artificial insemination in dairy cows, sheep and other farm animals (Burkea et al., 2001; Martínez et al., 2002). Although Directive 2003/74/EC, amending Directive 96/22/EC, permanently prohibited the use of estradiol-17 $\beta$ and its ester-like derivatives as growth promoters, a temporary exemption was given until 14 October 2006 for their use as an oestrous-induction tool in cows, horses, sheep or goats (EC, 2003). As alternative effective products exist and are implemented in the market (Lane et al., 2008; Vilariño et al., 2010), the European Parliament banned estradiol-17 $\beta$ and its ester-like derivatives, including those with a therapeutic purpose, in 2008 to ensure human health protection within the EU (EC, 2008). In the absence of estradiol-based products, alternatives for estrous synchronization are prostaglandin or the progesterone-releasing devices. Alternatives for the treatment of pyometra and endometritis could include the use of prostaglandins thanks to a combination of their direct ecbolic and luteolytic effects.

No estradiol-based drugs are in the European veterinary market anymore, except for its use in pets (EC, 2008). However, the possibility of widespread abuse of hormonal substances by unscrupulous farmers and veterinary professionals in some parts of Europe still exists, mainly due to the economic benefits that these substances provide in animal husbandry and the existence of authorized drugs in other non-European countries (Stephany, 2001). Limited research was found on the effects of anabolic implants in poultry, sheep, and pigs. Anabolic steroids are not approved for growth regulation in pigs in the United States (US) and numerous other countries. Even so, Lee et al., 2002 and Sheridan et al. 1999 studied the effect of anabolic steroids in pigs, concluding that they were not suitable agents to improve growth or carcass characteristics of pigs, but mid-back fat appeared reduced anyway (Lee et al., 2002; Sheridan et al., 1990). 


\subsection{Androgenic and gestagenic drugs}

Androgenic and gestagenic growth promotants approved in the US include steroid hormone anabolic implants with testosterone, progesterone, trenbolone and melengestrol acetate, all of them banned in EU. With the exception of melengestrol acetate, the recommended administration of these drugs is by subcutaneous implantation of continuously releasing hormone pellets in the ear. Androgenic hormones (testosterone and trenbolone acetate) directly reduce fat content of the carcass (Hunter, 2010) and have proved to be also effective in chicken to increase muscle quality and quantity (Chen et al., 2010). Medroxyprogesterone, chlormadinone, megestrol and melengestrol are synthetic analogues of progesterone that are commonly administered orally as acetate derivatives. They are used for synchronization of estrous, but have also been used as growth promoters in cattle. Although forbidden within the EU, the misuse of these natural and synthetic hormones is well known. For this illegal purpose they are frequently injected into the animal body as 'hormone cocktails' including new compounds each day, such as gestagens delmadinone acetate and algestone acetophenide (Daeseleire et al., 1994).

\section{Human health and hormones}

Endogenously synthesized steroid hormones exert a wide range of biological effects on the body and not only in the reproductive organs, which is why they are vital in normal development and life. Possible effects vary according to a number of factors such as gender and age, ethnicity and even environment. However, exogenous steroidogenically active compounds may interfere in the hormonal endogenous equilibrium affecting health and natural body development. As any other chemicals of natural or synthetic nature, hormones can be "toxic" to living organisms under certain circumstances, due to an excessive exposure at an abnormal stage during development or adult life. The current increasing trends of cancer and reproductive disorders have been frequently related to exogenous steroids food intake and endocrine disrupters that are present in the environment. The major areas of concern expressed in the literature are related to cancer, mutagenicity and reproductive effects, in particular endocrine disruption. Generally, cancer and mutagenicity are well described and well understood but endocrine disruption has become, in recent years, an area where there has been concern about potential harmful outcomes for a wide range of chemicals previously unsuspected of causing such effects.

As a matter of fact, the possible impact of exogenous steroid hormones, such as natural and synthetic hormones present in food products, are more dangerous for certain groups of population which are considered to be more sensitive and vulnerable than the rest. As regard to naturally occurring sex hormones, such as estradiol or testosterone, daily endogenous production and exogenous intake (in food) seem to be key points to evaluate risk. Taking children as reference population with the lowest levels of endogenous synthesis of steroids, an assessment of their plasmatic levels and of the presence of these chemicals in food are crucial. For this purpose, highly sensible and accurate techniques based on chromatography and mass spectrometry are required. Additionally, circulating levels of hormones have resulted to be lower than previously reported for prepubertal children and fetuses. First assessments of estradiol levels in serum of prepubertal boys and girls were based on radioimmunoassay (RIA) and its concentration appeared in most cases in a range of difficult accurate measurement, very close or even below conventional detection limit, 
resulting in overestimated values (Aksglaede et al., 2006; Bay et al., 2004). Tandem mass spectrometry methods in combination with gas chromatography or liquid chromatography for sex steroid hormones have been developed and are the methods of choice for the accurate measurement of the low levels of testosterone found in children and females and even the low levels of estradiol in postmenopausal women, men and the prepubertal child (Kushnir et al., 2010; Moal et al., 2007; Nelson et al., 2004; Stanczyk et al., 2007). Actually, the current and more sensitive assays, mainly mass-spectrometry-based analysis, have revealed that previous RIA values were in fact overestimated and sex steroids in children are extremely low (Courant et al., 2010). There are no limits for hormones which assure children's safety under exposure to exogenous steroids and endocrine disruptors. Furthermore hormonal changes or disruption during fetal life or puberty may provoke serious subsequent problems in their adult life. Since no safe threshold has been established yet, it seems necessary to avoid unnecessary children's and fetuses' exposure to exogenous disruptors, natural or synthetic, present in food even at very low levels (Bay et al., 2004).

Both exogenous hormones and synthetic compounds mimicking their effects may change the endogenous balance of human body, provoking disturb in their natural functions. As a result of their low endogenous levels, children are extremely sensitive to exogenous steroid hormones and small variations in blood levels might trigger serious pubertal development effects and even future adult life problems (Aksglaede et al., 2006; Alves et al., 2007). Several epidemiological studies have proved the existence of a trend to earlier puberty in American girls during last decades, and incidence is on the rise. In 1997, Hermann-Giddens et al. reported an unexpected advance in timing of puberty in both African-American and white American girls (Herman-Giddens et al., 1997). An advance in timing of onset of puberty has not been noted yet in other countries, although it is likely to become more prevalent as other countries adopt American lifestyle and diets (Parent et al., 2003). Precocious puberty has health and social implications, it is complex and influenced by multiple factors such as ethnicity, gender, nutrition, endocrine disrupting chemicals, pollutants and exogenous sex steroids (Aksglaede et al., 2006; Cesario \& Hughes, 2007; Daxenberger et al., 2001). However, there is a key difference between US and the rest of the world, since they still allow the use of some hormonal drugs in food producing animals. This fact might not be a bare coincidence and mean an increase on the exogenous intake of steroids for American children (Aksglaede et al., 2006; Partsch \& Sippell, 2001).

On the other hand, a tendency to increasing incidence of certain cancer types, such as testicle, breast and prostate cancer, has not been fully clarified yet, though sex hormones are suspected to play a key role (Foster et al., 2008; Huyghe et al., 2003; Prins, 2008; Wigle et al., 2008). For instance lung cancer, which is the leading cause of cancer deaths in the United States and has surpassed breast cancer as the primary cause of cancer-related mortality in women, has been related to estradiol along with tobacco consumption by Meireles et al. (Meireles et al., 2010). Estrogens have also been linked to other types of cancer such as squamous cell carcinoma of the head and neck (HNSCC), which is the sixth most common type of cancer in the United States (Shatalova et al., 2011). Estrogen exposure is one of the established risk factors for breast cancer, the most commonly diagnosed cancer in women (Zhong et al., 2011). An association between the risk of breast cancer and persistently elevated blood levels of estrogen and androgen has been found in many studies (Kaaks et al., 2005; Yager \& Davidson, 2006). Metabolites of zeranol, a non-steroidal anabolic growth 
promoter with potent estrogenic activity and widely used in the US, contained in meat produced from cattle after zeranol implantation, may be a risk factor for breast cancer (Zhong et al., 2011). Experimental and epidemiological data support a role for sex steroid hormones in the pathogenesis of endometrial cancer as well. As a matter of fact, circulating androgen levels were also related to endometrial cancer, although less strongly than circulating estrogen levels (Lukanova et al., 2004). However, the effect of elevated androgen (androstenedione and testosterone levels) on endometrial cancer risk seems to be mediated mainly through their conversion to estrogens.

As recently reported by Kvarnryd et al., progestogens exposure might have reproductive toxicity as well, in animals and humans, provoking defects on the development of female sex organs and subsequent infertility (Kvarnryd et al., 2011). The level of serum progesterone has not been associated with a risk of breast cancer in postmenopausal women, but in premenopausal women it appears to be inversely associated with the risk of breast cancer (Micheli et al., 2004). As for androgenic steroids, circulating concentrations of dehydroepiandrosterone (DHEA) and DHEA appear markedly decreased during aging, and thus this fact implicates the natural androgen in cognitive decline associated to age (Sorwell \& Urbanski, 2010). On the other hand, increased blood levels of DHEA and its sulphate have been found in schizophrenia patients, and apparently these levels are strongly correlated to the severity of illness and aggressive behaviour of patients and to the pathophysiology of other stress-related psychiatric disorders (Garner et al., 2011; Strous et al., 2004).

As regard to hormonal content, all foodstuff of animal origin contains steroid hormones and metabolites, but their concentrations vary with the kind of food, species, gender, age and physiological stage of the animal (Daxenberger et al., 2001; Poelmans et al., 2005a, 2005b). As a matter of fact, meat is clearly one of the most naturally 'contaminated' foods (Maume et al., 2001; Maume et al., 2003; Poelmans et al., 2005a). Data published by Swan et al. in 2007 already suggested that maternal beef consumption may alter males' testicular development in utero and adversely affect his adult reproductive capacity (Swan et al., 2007). Even milk consumption, the hormone content of which is well known, has been associated with an increased risk of early menarche (Wiley, 2011). There are studies that find a relationship between milk and dairy products with human illnesses, such as teenagers' acne, prostate, breast, ovarian and corpus uteri cancers, many chronic diseases that are common in Western societies, as well as male reproductive disorders (Adebamowo et al., 2008; Ganmaa et al., 2011; Ganmaa et al., 2001; Givens et al., 2008; Melnik, 2009; Wiley, 2011). There are many possible contributory factors to these health problems, including steroid hormones which are well known as endocrine disruption agents. In this field, some studies have arisen regarding sex hormone levels in milk in relation to animals' pregnancy, most of them regarding estrogens and androgens (Courant et al., 2007; Farlow et al., 2009; Ganmaa \& Sato, 2005; Maruyama et al., 2010; Pape-Zambito et al., 2010). Cow's milk contains considerable quantities of hormones and is therefore of particular concern (Courant et al., 2007). It is a fact that dairy milk consumption by humans started around 2000 years ago, but the milk which people drink today is quite different from traditional milk. As a result of modern farming and animal breeding, today's milk originates from genetically improved dairy cows such as Holstein, which are pregnant during most of their lactation period (Maruyama et al., 2010).

Regarding potential toxicological substances used in animal husbandry, for the endogenous sex steroids and their simple ester derivatives the US Food and Drug Administration (FDA) 
concluded that 'safety can be assured' because they are endogenous in both food-producing animals and people. Additionally, they stated that '...no additional physiological effect will occur in individuals chronically ingesting animal tissues that contain an increase of endogenous sex steroids from exogenous sources equal to $1 \%$ or less of the amount in micrograms produced by daily synthesis in the segment of the population with the lowest daily production. We believe that the $1 \%$ value is supported by scientific evidence, is reasonable, and reflects sound public health policy. For estradiol and progesterone, prepubertal boys provide the baseline benchmark. For testosterone, prepubertal girls provide the baseline benchmark...' (U.S. Department of Health and Human Services, 2006). The FDA stated that although not all sex steroids are demonstrated carcinogens, they should be regarded as suspect carcinogens. As a matter of fact, the FDA concluded that to establish the safety of a synthetic steroid animal testing is necessary. However, to show the safety of an endogenous sex steroid, the sponsor simply have to demonstrate that, under the proposed conditions of use, the concentration of residue of the endogenous steroid in treated food-producing animals is such that the increase will not exceed this $1 \%$ permitted increase. The Joint Food and Agricultural Organisation/World Health Organisation (FAO/WHO) Expert Committee on Food Additives (JECFA) and the US Food and Drug Administration (FDA) considered, in 1988, that the residues found in meat from treated animals were safe for the consumers. However, current recommendations might be overestimated and should be revised, altogether with hormonal levels in children. The lack of known proved hormonal thresholds, under which value no effects could be observed in humans, add uncertainty to this issue.

\section{Legal implications}

The use of hormonal growth promoters to increase the production of muscle meat has led to international disputes about the safety of meat originating from animals treated with such anabolics. Implants containing anabolic steroids are widely used in the US beef industry, among other countries, to fast growth and finish cattle and to improve feed efficiency. Growth promotants approved in the US include steroid hormone anabolic implants (17 $\beta$ estradiol, testosterone, progesterone, trenbolone, zeranol, melengestrol acetate) and $\beta$ agonist feed additives (ractopamine) for finishing swine, cattle and turkeys, all of them banned in EU (U.S. FDA, 2010). With the exception of melengestrol acetate, the recommended administration of estradiol, progesterone, and testosterone (three natural hormones), and zeranol and trenbolone acetate (two synthetic hormones) is by subcutaneous implantation of continuously releasing hormone pellets in the ear. This ear would be then discarded during slaughtering but there is no withdrawal time for any of these legally approved implants. Melengestrol acetate is approved for its use as a feed additive. As a result of the existence of these legal drugs, a significant part of cattle raised in US feedlots are treated with growth promoting sex hormones. Over $97 \%$ of cattle weighing $700 \mathrm{lbs}$ or more received at least one anabolic implant during the finishing period in 1999 (Salman et al., 2008). In general, a decrease on the use of growth promoting implants in US cattle over the past twenty years has been observed. More than one of four farms implanted some calves with growth promotants prior or at weaning in 1992, but fewer than one of eight did so in 2007 (USDA, 2009). The reason of this decline on the use of implanting, a profitable US management practice, could be the publicity surrounding hormonal implants 
and movement toward marketing cattle in natural or organic programs. The most used substances are estrogenic drugs, in the form of estradiol-17 $\beta$, estradiol benzoate or the synthetic zeranol. Progesterone, testosterone and the two synthetic chemicals trenbolone acetate and melengestrol acetate are generally used in combination with estrogens. It is also a standard legal practice to use hormones to promote the growth of cattle in the meat industry in Australia (Hunter, 2010). These chemicals are approved, registered and regulated by the Australian Pesticides and Veterinary Medicines Authority (APVMA) which, as well as US Food and Drug Administration (FDA), keeps its position on saying that they are safe for consumers, not harmful to animals and effective when used according to label instructions. As a consequence, regulatory controls would differ sharply between the $\mathrm{UE}$ and the countries where hormonal active growth promoters are still legal.

The European ban of the use of hormones arose in the 70s due to the health consequences derived from the use of diethylstilbestrol (DES), a synthetic estrogen widely administered to women to prevent miscarriage and other pregnancy complications. This chemical led to reproductive problems in treated women, as well as reproductive alterations, gynecologic cancer and malformations in reproductive organs in their female children, above normal average values (Auclair, 1979; Cousins et al., 1980; Haney \& Hammond, 1983; Rosenfeld \& Bronson, 1980). In 1980, European consumer organizations called for a boycott of beef as a result of widespread publicity involving illegal use of diethylstilbestrol in European veal production. In response, EC agriculture ministers agreed to ban the use of hormones for raising livestock with the enactment of the first legal European ban of hormones in 1981 (EEC, 1981), with the adoption of restriction in livestock production prohibiting the use of synthetic hormones and substances having a hormonal activity and limiting the use of natural hormones to therapeutic purposes. The Directive 81/602/EEC prohibited the use of certain substances having hormonal action (estradiol-17 $\beta$, progesterone, zeranol, trenbolone acetate, melegestrol acetate or MGA) and thyrostatic, as growth promoters in farm animals. However, the Council recognized that five of the hormones at issue here (all but MGA) were of a different status than the other banned hormones and directed the Commission to provide a report on the experience acquired and scientific developments, accompanied, if necessary, by proposals which take these developments into account. In the meantime, the individual Member State regulations would continue to apply to the use of these five hormones.

Seven years later, the Directive 88/146/EEC was enacted, aiming at banning the administration of synthetic hormones (zeranol and trenbolone acetate) with any purpose, and natural hormones (estradiol, progesterone and testosterone) to promote growth in cattle (EEC, 1988a). This Directive allowed State Members to authorize the administration of those natural hormones, under certain circumstances, with therapeutic and zootechnical purposes. Both intra community trade and importation from non-European countries of meat and meat products from animals treated with chemicals with estrogenic, progestogenic and androgenic or thyrostatic effects were specifically forbidden with Directive 88/146/EEC. Meat from animals treated with a therapeutic or zootechnical purpose was allowed under certain circumstances, established with Directive 88/299/EEC (EEC, 1988b). In 1996, Directive 96/22/EC, a revision and repealing of previous hormone Directives, established the ban of substances having thyrostatic, estrogenic, androgenic and gestagenic action in animal husbandry and aquaculture (EC, 1996a). The Directive 96/23/EC on measures to monitor certain substances and residues thereof in live animals and animal products, was 
released to establish that Member States should draft a national residue monitoring plan for the groups of substances detailed in its Annex I (EC, 1996b). These plans had to comply with the sampling rules in Annex IV to the Directive. It also established the frequencies and level of sampling and the groups of substances to be controlled for each food commodity. This Directive included the control of a wide range of veterinary drugs in food producing animals and goods derived from them, such as meat, eggs and honey. In Annex I, substances were classified in two groups: group A included substances having anabolic effect and unauthorized substances, and group B included authorized veterinary drugs, the MRL of which have been established, and contaminants. So that for residues of substances from group A, a 'zero tolerance' applied.

In 2003, the Council Directive 2003/74/EC amended Directive 96/22/EC and narrowed circumstances under which estradiol-17 $\beta$ and its ester-like derivatives could be administered, under strict veterinary prescription and for non-growth-promoting purposes (treatment of foetus maceration or mummification or treatment of pyometra in cattle, and in oestrus induction in cattle, horses, sheep or goats until 14 October 2006) (EC, 2003). Those authorized treatments had to be carried out by the veterinarian himself or herself on farm animals which have been clearly identified, and had to be registered by the veterinarian responsible. Lately, the Council Directive 2008/97/EC was enacted to take into account the European Protocol on protection and welfare of animals, limiting the scope of Directive 96/22/EC only to food-producing animals and withdrawing the prohibition for pet animals, as well as to adjust the definition of therapeutic treatment (EC , 2008). As a matter of fact, an efficient control of residues is an essential contribution to the maintenance of a high level of consumer protection in the EU and it was necessary to provide clear rules on how laboratory analysis had to be carried out and results interpreted. That was achieved with Commission Decision 2002/657/EC, implementing Council Directive 96/23/EC, which established criteria and procedures for the validation of analytical methods to ensure the quality and comparability of analytical results generated by official laboratories (EC, 2002). Moreover, the Decision established common criteria for the interpretation results and introduced a procedure to establish minimum required performance limits (MRPL) for analytical methods employed to detect substances for which no permitted limit (MRL) had been established. This is in particular important for substances whose use is not authorized or is specifically prohibited in the EU, such as hormonally active substances. For the first time, the concepts of decision limit (CCa) and detection capability (CC $\beta$ ) were introduced, as quality parameters that must be established during the validation of an analytical method. Currently, the evolution in analytical equipment and progress in scientific research, accompanied by recent European regulatory changes, seems to demand an update or revision of the 2002/657/EC (Vanhaecke et al., 2011).

Unlike in European countries, a number of steroidogenic drugs, which are used as hormonal growth promoters, are registered for use in many countries including Australia, New Zealand, United States and Canada, among others. However, the EU has been constantly banning their use since early 80s with Directive 81/602/EEC and neither allows the importation of products from cattle given growth promoters. In 1998, the World Trade Organization (WTO) found the European ban not supported by scientific evidence and inconsistent with its WTO obligations, but Europe continues arguing consumers' concerns, 
animal welfare and meat quality so that its rule remains in place currently. Although the World Trade Organization has issued decisions that have questioned the validity of the European ban, the EU has repeatedly voted to maintain it, citing consumer worries, questions of animal welfare and meat quality.

\section{Beef hormone: US versus EU and trade dispute}

Growth hormones are used extensively around the world to enhance the performance of beef cattle. In 1981 the European Union adopted first restrictions on the use of hormones as growth promoters in beef production with Directive 81/602/EEC, the first hormone directive (EEC, 1981). This directive prohibited the utilization of stilbenes and thyrostatics, two hormonal substances presumed to have harmful effects. Later in 1989 the EU fully implemented ban on imports of meats treated with enhancing hormones, expanding their restrictions to other non-European countries wishing to export meat to EU and that would assume many of the rights and obligations of European single market. The ban of imported hormone-beef arose from European consumers' pressure more than from producers, and it meant great losses for the US meat industry. The EU justified the ban as needed to protect the health and safety of consumers from the illegal and unregulated use of hormones in livestock production in several European countries. During the 1980s, there were widespread press reports of black market sales of 'hormone cocktails' by a 'hormone mafia' as well as several reports of serious health effects from consuming meat from animals treated with enhancing hormones. Many European livestock producers support the hormone ban because of the possible existence of competition from cheaper imported beef from beef exporting countries using hormones to breed animals. Also consumers' increasing demand of hormone-free meat creates concerns among European farmers about maintaining the ban. Certain circumstances, such as the Italian hormone crisis (Loizzo et al., 1984; Loizzo, 1984) and the outbreak during the 1990s of bovine spongiform encephalopathy (BSE), so called 'mad cow disease', added consumer distrust about the safety of beef supply. Although the BSE problem had nothing to do with hormones, it also contributed further to an unfavourable politic-economic and social environment for resolving the beef hormone dispute between EU and US and Canada.

For the past 15 years, the United States and the European Union have been disputing the safety of growth promotants used in cattle. The disagreement over the use of hormones started when the EU banned the import of beef from cattle treated with hormones in 1989, cutting off exports of beef. Unlike EU, the use of natural hormones in farm animals keeps avoiding any legal ban as the US Food and Drug Administration (FDA) says use of hormones is 'safe and scientifically backed up with research'. Since the 1950s, the FDA has approved a number of steroid hormone drugs for use in farm animals, including estradiol, progesterone, testosterone, and their synthetic versions zeranol, melengestrol acetate and trenbolone acetate. FDA claims that people are not at risk eating food from animals treated with these drugs because the amount of additional hormone following drug treatment is very small compared with the amount of natural hormones that are normally found in the meat of untreated animals and that are naturally produced in the human body. Consequently, hormones have continued to be used to promote growth in beef cattle both legally in the US and elsewhere in the world and illegally within the EU. 
In response to US threats to challenge the ban in early 1996, the European Parliament voted unanimously to keep it, citing consumers' concerns, animal welfare and meat quality, among other reasons. European farm ministers from different EU countries also supported the ban, only the Minister of Agriculture of UK voted to end it arguing that there was no scientific basis to maintain it. The trade dispute took turn in 1996 when US presented its case against EU hormone ban to the World Trade Organization (WTO). The WTO, a disputesettlement mechanism born in 1995, found that the European ban was not based on evidence in 1997. However, the European Commission (EC) appealed against this statement and sponsored research studies to clarify the risk for consumers of hormonally active substances applied in food producing animals. Altogether six substances were at issue in the dispute, three naturally occurring hormones (estradiol-17 $\beta$, testosterone, and progesterone) whose level in animals can vary significantly, depending on age, sex, and sexual development of the animal, among other factors, and three synthetic substances (trenbolone, zeranol, and melengestrol acetate) that are produced synthetically to mimic the effect of the three naturally occurring hormones. The EC's Scientific Committee on Veterinary Measures relating to Public Health (SCVPH) concluded that the risk from hormone-treated food was higher than previously thought and proposed that there was a significant body of scientific evidence suggesting that $17 \beta$-estradiol should be considered a complete carcinogen. It also concluded that there were risks to consumers from the other five hormones examined and no threshold concentrations could be defined. The EU invoked the precautionary principle as a rationale for its banning the import of beef produced using hormones. The Agreement on Application of Sanitary and Phyto-sanitary Measures (SPS) permits precautionary measures when a government considers the scientific evidence insufficient to permit a final decision on the safety of a product, as is the case of hormonally produced food. The WTO Panel upheld US position and the EU was given until May 131999 to bring its measure into compliance. However, the EU Commission voted again unanimously to continue the ban. In maintaining its unscientific ban, the EU does nothing to further the objective of protecting public health, but instead undermines the WTO Sanitary and Phytosanitary Agreement (SPS) and invites other countries to renege on their international obligations.

Despite the attempts of US to solve this dispute, the EU reaffirmed its position that there is a possible risk to human health associated with hormone-treated meat, basing on available scientific data. To date, the EU continues to ban import of meat from animals treated with hormones and only imports high-quality beef certified as produced without the use of hormones. However, on May 13 in 2009, following a series of negotiations, the United States and the EU signed in Geneva a memorandum of understanding (MOU) implementing an agreement that could resolve this longstanding dispute. Under MOU the EU expanded the market access of US beef, at zero duty, from cattle raised under control measures specified in USDA's Non-Hormone Treated Cattle (NHTC) program, from cattle grown in approved farms/feedlots. To become eligible to export non-treated beef, producers must obtain certification for their cattle through the NHTC program. Meanwhile, the US and Canada continue retaliating against the EU hormone ban based on the additional costs of producing non-hormone treated beef for the European Union and the lack of evidence of its harmful effects in humans. Despite all the US controversy, in a survey of US consumers it was found that most respondents desired the existence of mandatory labelling of food produced with growth hormones, even when labelling costs causing beef prices increase up to $17 \%$ (Lusk \& Fox, 2002). While the dispute is between Canada and the US and the EU, other important 
beef-producing countries have approved the use of growth-promoting hormones in beef production such as Canada, New Zealand, South Africa, Mexico, Chile, and Japan, among others. Like for US meat, thigh controls are in place to ensure all beef exported to EU comes from non-hormone treated cattle.

\section{Progress on analytical methodology}

During the past few years, many authors have described the application of LC-MS/MS methods for the analysis of anabolic steroids in various biological samples, including urine, serum, hair, kidney and fat (Draisci et al., 2000; G. Kaklamanos et al., 2009a; Kaklamanos et al., 2009b; Kaklamanos et al., 2011; Shao et al., 2005), all validated according to the criteria set out in Decision 2002/657/CE for banned substances. Although normally the levels of steroids that accumulate in animal tissues are lower than in other matrices, many effective methods are known currently for the determination of these compounds in muscle tissue, sometimes monitoring a wide range of anabolic compounds (Courant et al., 2008; Kaklamanos et al., 2007; Vanhaecke et al., 2011; Yang et al., 2009). Since the number of growth promoters is high and includes natural and synthetic compounds, the use of multianalyte techniques is becoming more interesting (Vanhaecke et al., 2011; Xu et al., 2006; Yang et al., 2009). The use of ultra-resolution liquid chromatography techniques (UPLC), coupled to mass spectrometry devices, provides a rapid separation of analytes, shortening analytical times and improving the simultaneous detection of multiple steroids (Stolker et al., 2008; Vanhaecke et al., 2011).

\subsection{Synthetic and semi-synthetic steroids}

Synthetic hormones are xenobiotic substances that do not naturally occur in animal organisms. These exogenous drugs mimic the effects of natural endogenous hormones, such as the case of synthetic versions of estradiol, progesterone and testosterone: zeranol, melengestrol acetate (MGA) and trenbolone acetate, respectively. In general and due to their entirely exogenous character, since these compounds do not exist naturally, there are no major difficulties in determining analytic synthetic steroids. Thus, their mere presence in the animal organism is a clear evidence their administration. With regard to the confirmation of use of xenobiotic analogues of natural sex steroids and non-steroidal compounds, such as stilbenes and zeranol, there is an extensive range of successful methods that has been performed on different analytic matrices. These analytical procedures have made the confirmation of illicit administrations of anabolics in cattle feasible (De Brabander et al., 2007; Duffy et al., 2009; Kaklamanos et al., 2011; Noppe et al., 2008).

On the other hand, many veterinary hormonal preparations, although not all, consist on ester derivatives of the corresponding endogenous steroid, such as testosterone decanoate or estradiol benzoate. As hormonal esters do not naturally occur in the animal organism, the detection of these synthetic substances in the body of an animal provides irrefutable evidence of the abuse of these promoters. Although the administration of esters of natural hormones can be detected through hair analysis (Duffy et al., 2008; Gratacós-Cubarsí et al., 2006; Pedreira et al., 2007; Rambaud et al., 2005), it has been very difficult to detect intact steroid esters in body fluids or tissues. It is likely that esters quickly hydrolyze in the body of the animal, releasing the corresponding natural hormone (Stolker et al., 2009). So, the 
simple detection and confirmation of the presence of these semisynthetic versions are not always possible. That is particularly true for estradiol benzoate, which has only been detected in hair up to date (Duffy et al., 2009; Hooijerink et al., 2005; Rambaud et al., 2005; Stolker et al., 2009), because estradiol benzoate undergoes the loss of the ester group once it reaches the bloodstream. In order to detect the administration of these esterified substances, new analytical approaches are required, in the same manner that they are required to detect the administration of exogenous hormones in their natural chemical form (estradiol, testosterone or progesterone).

\subsection{Exogenous natural steroid hormones}

Hormones of natural origin, such as estradiol- $17 \beta$, testosterone or progesterone, are still a weak area in residue-monitoring plans due to their endogenous origin, as the target compound is always present. In such a case, the confirmation of an exogenous administration involves logical difficulties associated with distinguishing an exogenous origin from an endogenous (naturally occurring) presence of these hormones. The demonstration of an exogenous administration of natural steroids, such as testosterone, estradiol or cortisol, remains problematic. No official threshold has been stated for natural hormone concentrations, mainly due to the fact that concentrations of naturally occurring hormones are highly variable and depend on the type of animal product, breed, gender, age, disease, medication and physiological condition (Angeletti et al., 2006; Hartmann et al., 1998; Le Bizec et al., 2009; Pleadin et al., 2011). The development of methods to provide unequivocal discrimination between the natural presence of an endogenous hormone and its presence as a consequence of an illegal exogenous administration remains a challenge. Some promising analytical approaches have been published in the past few years regarding this critical point of controlling residues in food of animal origin.

\section{Monitoring exogenous natural hormones: An unresolved problem}

The confirmation of an exogenous administration of natural hormones involves logical difficulties associated with the distinction between an exogenous origin and the natural presence of these endogenous hormones (synthesis in the body). In fact, it has been found that treatments with testosterone or estradiol in bovines lead to equal or lower plasma concentrations of these compounds (Scippo et al., 1994; Simontacchi et al., 2004). On the other hand, exogenous natural hormones are usually administered as simple semi-synthetic esters (i.e., $17 \beta$-estradiol benzoate and testosterone decanoate) to increase their effective half-life. Subsequently, a rapid hydrolysis of these compounds takes place as soon as they reach the bloodstream, where they generate non-esterified forms that are indistinguishable from naturally occurring forms (Stolker et al., 2009). These exogenous natural compounds (or even hormonal esters) follow the same pathways as the natural compounds biosynthesized by the animal, making the detection and confirmation of their exogenous administration difficult, if not impossible. These circumstances have led to the lack of success in detecting hormone esters such as estradiol benzoate in serum or plasma, which has only been confirmed in hair from animals treated with this ester (Duffy et al., 2009; Regal et al., 2008). Some promising approaches have been published in recent years in regard to the development of methods that allow unambiguous discrimination between the presence of a natural endogenous hormone and its presence as a result of an illegal exogenous administration. 


\subsection{Approaches based on hormonal metabolism}

Up to date, it is unknown to what extent the administration of exogenous hormones interferes with the hormonal metabolism of the animal. When administered exogenously, natural steroid hormones must be metabolized in the same way and using the same metabolic pathways that endogenous compounds, so that the ratios of these hormones against their precursors and/or their metabolites may be somehow altered by the hormonal treatment (Pinel et al., 2010). This analytical approach is already a common practice in the supervision of doping in sports and horse racing (Sottas et al., 2008; Strahm et al., 2009; Torrado et al., 2008). However, the known approaches based on metabolic parameters that have proved to be useful in humans, as the ratio testosterone/epitestosterone, not seem to succeed in cattle (Angeletti et al., 2006). Early attempts to detect illegal hormone treatments in cattle assessing hormonal levels and levels of their precursors and metabolites (and hormonal ratios) appeared in plasma and urine of cattle (Becue et al., 2010; Fritsche et al., 1999; Simontacchi et al., 2004). In 1999, Fritsch et al. concluded that implants of estradiol benzoate and progesterone did not to affect the total concentration of steroids (precursors and metabolites) in meat from treated cattle. However, they encountered significant differences in $17 \beta$-estradiol/17a-estradiol+Estrone ratio and in cortisone/hydrocortisone ratio; so that the administration of natural hormones did seem to influence the hormonal metabolism (Fritsche et al., 1999). On the other hand, Maume et al. concluded that estradiol implants increased the concentration of $17 \beta$-estradiol $\left(\mathrm{E}_{2}\right)$ in beef, following a dose-dependent relationship. Besides, the concentrations of $E_{2}$ and $\mathrm{aE}_{2}$ glucuronides were also increased in tissues of treated animals, an effect also being dosedependent (Maume et al., 2003). As for the administration of steroid precursors or prohormones, Becue et al. recently published results in urine for cattle treated with DHEA orally or intramuscularly. They concluded that the administration of DHEA causes significant differences in overall levels of DHEA sulphate and 5-androstenediol, and also in the levels of free DHEA and 17a-testosterone in animals treated orally. DHEA levels, both free and sulphate, 5-androstenediol and 17a-testosterone were modified for animals treated via intramuscular (Becue et al., 2010).

\section{$7.2{ }^{13} \mathrm{C} /{ }^{12} \mathrm{C}$ isotopic ratio}

The measurement of ${ }^{13} \mathrm{C} /{ }^{12} \mathrm{C}$ ratios by gas chromatography/combustion/isotope ratio mass spectrometry (GC-C-IRMS) can be a powerful tool to trace the true origin of the steroids, and it is one of the most promising approaches to control of exogenous administration of natural hormones. The administration of natural hormones to cattle will lead to an alteration of the ${ }^{13} \mathrm{C} /{ }^{12} \mathrm{C}$ ratio of these compounds and their metabolites, whereas the isotopic composition remains constant for their precursors. This methodology has been applied successfully in urine to trace the administration of testosterone and estradiol esters in cattle (Buisson et al., 2005; Hebestreit et al., 2006). However, no thresholds of reference for these changes in the 13C/12C ratios of steroid hormones have been established yet, since their variations depend largely on the diet of the animal and also other factors such as age, sex or breed (Cawley et al., 2009; Ferchaud et al., 2000). In addition, GC-C-IRMS methods imply long and complicated steps of extraction and purification of the sample and also the use of semi-preparation HPLC and derivatization procedures (Buisson et al., 2005; Hebestreit et al., 2006). 


\subsection{Omic technologies: Metabolomics}

In recent years, there is a clear trend towards more intelligent procedures for data evaluation. New methodological approaches based on untargeted and global measurements are emerging strongly as analytical tools for the analysis of residues in food-producing animals (Pinel et al., 2010; Riedmaier et al., 2009). Traditionally, samples are analyzed searching for the presence of specific target analytes. Metabolomics is an emerging field within the omic methodologies (proteomics, transcriptomics, metabolomics) that focuses, in an untargeted and global scale, in the high yield measurement of small molecules (called metabolites) in biological matrices. These techniques are based on the physiological changes that are expected to appear in the animal due to the administration of an anabolic agent, and they are largely used to search potential biomarkers of such administration (Mooney et al., 2008; Mooney et al., 2009; Riedmaier et al., 2009). Metabolomics is based on detecting small molecules and excluding big biopolymers such as proteins, generating this way a large set of descriptors characteristic of the biological matrix under investigation in different experimental groups. Metabolomic approaches have already shown to be affective in relation to different biochemical processes, such as drug toxicity and diseases (Brindle et al., 2002; Coen et al., 2003; Lindon et al., 2004; Vallejo et al., 2009), prediction of gender (Lutz et al., 2006), nutritional effects studies (Wang et al., 2005) and even doping control in horses (Kieken et al., 2011) or the clenbuterol use in cattle (Courant et al., 2009). Basically, the general principle of metabolomic studies is the characterization of the biological system or sample in question through the generation of metabolomic fingerprints.

There are not many metabolomics studies regarding the detection of sex steroid abuse in livestock production, neither useful biomarkers to be used in targeted analysis. However, Rijk et al. developed a metabolomic strategy of screening in urine for bovine animals treated with DHEA and pregnenolone. This methodology is an useful tool to track the abuse of these prohormones, but their reference levels remain unknown, making difficult their use in targeted analysis, at least until the metabolites of this non-focused approach are elucidated (Rijk et al., 2009). On the other hand, Dervilly-Pinel et al. recently published a metabolomic study in urine for cattle treated with a combination of estradiol benzoate and nandrolone laureate. These authors proved the existence of changes in urinary metabolomic profiles of animals treated with steroids, when comparing them with control animals, opening the door to possible screening strategies. Dervilly-Pinel et al. also stated the importance of several potential biomarkers in the discrimination of hormonally treated animals from control cattle (Dervilly-Pinel et al., 2011).

There is a range of analytical platforms which could be employed in metabolomics to collect data, including gas chromatography-mass spectrometry (GC-MS), liquid chromatographymass spectrometry (LC-MS) and nuclear magnetic resonance (NMR) spectrometry, just to extract as much information as possible from the matrix of interest. Traditionally, NMR has played a key role in the development of metabolomics and was the preferred analytical tool. However, due to the higher sensitivity compared to NMR and the increasing reproducibility of today's GC-MS and LC-MS systems, the have become important analytical platforms for all types of metabolomic applications (Brown et al., 2009; Lutz et al., 2006). By coupling high chromatography separation with different mass spectrometric techniques, the partial or complete separation of metabolites prior to detection is achieved. To this end, gas chromatography was first used, however, the necessary thermal stability of the investigated 
compounds, the required derivatization of non-volatile compounds prior to analysis and the frequent absence of molecular ions have made liquid chromatography coupled to atmospheric-pressure ionization a more and more used tool for metabolomics. Last generation of high resolution devices including time of flight and orbitrap instruments are becoming more and more used in this field due to their high performance in terms of sensitivity and specificity (Dunn et al., 2008; Scheltema et al., 2008).

Moreover, due to the large amount of data generated during metabolomic fingerprinting, bioinformatics tools are required for processing and analysing this huge volume of complex data. Several software solutions are today available either with free access (XCMS, MZmine, Metalign, MathDAMP, COMSPARI and METIDEA) or commercially (SIEVE from Thermo Fisher Scientific, Markerlynx from Waters, GeneSpring from Agilent and MarkerView from MSDSciex). Data processing is composed of four major steps; background noise correction, peak alignment, peak deconvolution and peak sorting. Then, resulting data are of multivariate character, since metabolomic procedures handle several hundreds to thousands of variables/metabolites. Thus the use of multivariate statistical techniques are required to analyse such data set and finally to point out potential signals (i.e. biomarkers) of interest. Principal component analysis (PCA) has become a popular tool for visualizing datasets and for extracting relevant information, as well as partial least-squares projection to latent structures (PLS) (Eriksson et al., 2004). Recently, the Orthogonal PLS methodology (OPLS) has shown to be useful for elucidating differences between many samples and many variables (Pohjanen et al., 2007; Werner et al., 2008).

\section{References}

Adebamowo, C. A.; Spiegelman, D.; Berkey, C. S.; Danby, F. W.; Rockett, H. H.; Colditz, G. A.; Willett, W.C. \& Holmes, M.D. (2008). Milk consumption and acne in teenaged boys. Journal of the American Academy of Dermatology, Vol.58, No.5, pp. 787-793.

Aksglaede, L.; Juul, A.; Leffers, H.; Skakkebæk, N. E. \& Andersson, A. (2006). The sensitivity of the child to sex steroids: Possible impact of exogenous estrogens. Human Reproduction Update, Vol.12, No.4, pp. 341-349.

Alves, C.; Flores, L. C.; Cerqueira, T. S. \& Toralles, M. B. P. (2007). Environmental exposure to endocrine disruptors with estrogenic activity and the association with pubertal disorders in children. Cadernos Saude Publica, Vol.23, No.5, pp. 1005-1014.

Angeletti, R.; Contiero, L.; Gallina, G. \& Montesissa, C. (2006). The urinary ratio of testosterone to epitetosterone: A good marker of illegal treatment also in cattle? Veterinary Research Communications, Vol.30, Suppl.1, pp. 127-131.

Auclair, C. A. (1979). Consequences of prenatal exposure to diethylstilbestrol. Journal of Obstetric, Gynecologic, and Neonatal Nursing, Vo.8, No.1, pp. 35-39.

Bay, K.; Andersson, A. \& Skakkebaek, N. E. (2004). Estradiol levels in prepubertal boys and girls - analytical challenges. International Journal of Andrology, Vol.27, No.5, pp. 266273.

Becue, I.; Van Poucke, C.; Rijk, J. C. W.; Bovee, T. F. H.; Nielen, M. \& Van Peteghem, C. (2010). Investigation of urinary steroid metabolites in calf urine after oral and intramuscular administration of DHEA. Analytical and Bioanalytical Chemistry, Vol.396, pp. 799-808. 
Boles, J. A.; Boss, D. L.; Neary, K. I.; Davis, K. C. \& Tess, M. W. (2009). Growth implants reduced tenderness of steaks from steers and heifers with different genetic potentials for growth and marbling. Journal of Animal Science, Vol.87, pp. 269-274.

Brindle, J. T.; Antti, H.; Holmes, E.; Tranter, G.; Nicholson, J. K.; Bethell, H. W. L.; Clarke, S.; Schofield, P.M.; McKilligan, E.; Mosedale, D.E. \& Grainger, D.J. (2002). Rapid and non-invasive diagnosis of the presence and severity of coronary heart disease using $1 \mathrm{H}$ NMR -based metabonomics. Nature Medicine, Vol.8, No.12, pp. 1439-1444.

Brown, M.; Dunn, W. B.; Dobson, P.; Patel, Y.; Winder, C. L.; Francis-McIntyre, S.; Begley, P.; Carroll, K.; Broadhurst, D.; Tseng, A.; Swainston, N.; Spasic, I.; Goodacre, R. \& Kell, D.B. (2009). Mass spectrometry tools and metabolite-specific databases for molecular identification in metabolomics. Analyst, Vol.134, No.7, pp. 1322-1332.

Buisson, C.; Hebestreit, M.; Weigert, A. P.; Heinrich, K.; Fry, H.; Flenker, U.; Banneke, S.; Prevost, S.; Andre, F.; Schaenzer, W.; Houghton, E. \& Le Bizec, B. (2005). Application of stable carbon isotope analysis to the detection of 17 beta-estradiol administration to cattle. Journal of Chromatography A, Vol.1093, No.1-2, pp. 69-80.

Burkea, C. R.; Mussardb, M. L.; Grumb, D. E. \& Day, M. L. (2001). Effects of maturity of the potential ovulatory follicle on induction of oestrus and ovulation in cattle with oestradiol benzoate. Animal Reproduction Science, Vol.66, No.3-4, pp. 161-174.

Cavalieri, J.; Rabiee, A. R.; Hepworth, G. \& Macmillan, K. L. (2005). Effect of artificial insemination on submission rates of lactating dairy cows synchronised and resynchronised with intravaginal progesterone releasing devices and oestradiol benzoate. Animal Reproduction Science, Vol.90, No.1-2, pp. 39-55.

Cawley, A. T.; Trout, G. J.; Kazlauskas, R.; Howe, C. J. \& George, A. V. (2009). Carbon isotope ratio $(\delta 13 \mathrm{C})$ values of urinary steroids for doping control in sport. Steroids, Vol.74, pp. 379-392.

Cesario, S. K. \& Hughes, L. A. (2007). Precocious puberty: A comprehensive review of literature. Journal of Obstetric, Gynecologic, E Neonatal Nursing, Vol.36, No.3, pp. 263274.

Chen, T. T.; Huang, C. C.; Lee, T. Y.; Lin, K. J.; Chang, C. C. \& Chen, K. L. (2010). Effect of caponization and exogenous androgen implantation on muscle characteristics of male chickens. Poultry Science, Vol.89, No.3, pp. 558-563.

Coen, M.; Lenz, E. M.; Nicholson, J. K.; Wilson, I. D.; Pognan, F. \& Lindon, J. C. (2003). An integrated metabonomic investigation of acetaminophen toxicity in the mouse using NMR spectroscopy. Chemical Research in Toxicology, Vol.16, No.3, pp. 295-303.

Courant, F.; Aksglaede, L.; Antignac, J.P.; Monteau, F.; Sorensen, K.; Andersson, A.; Skakkebaek, N.; Juul, A. \& Le Bizec, B. (2010). Assessment of circulating sex steroid levels in prepubertal and pubertal boys and girls by a novel ultrasensitive gas chromatography-tandem mass spectrometry method. Journal of Clinical Endocrinology and Metabolism, Vol.95, No.1, pp. 82-92.

Courant, F.; Antignac, J.P.; Laille, J.; Monteau, F.; Andre, F. \& Le Bizec, B. (2008). Exposure assessment of prepubertal children to steroid endocrine disruptors, 2: Determination of steroid hormones in milk, egg, and meat samples. Journal of Agricultural and Food Chemistry, Vol.56, No.9, pp. 3176-3184.

Courant, F.; Antignac, J.P.; Maume, D.; Monteau, F.; Andre, F. \& Le Bizec, B. (2007). Determination of naturally occurring oestrogens and androgens in retail samples of milk and eggs. Food Additives and Contaminants, Vol.24, No.12, pp. 1358-1366. 
Courant, F.; Pinel, G.; Bichon, E.; Monteau, F.; Antignac, J.P. \& Le Bizec, B. (2009). Development of a metabolomic approach based on liquid chromatography-high resolution mass spectrometry to screen for clenbuterol abuse in calves. Analyst, Vol.134, pp. 1637-1646.

Cousins, L.; Karp, W.; Lacey, C. \& Lucas, W. E. (1980). Reproductive outcome of women exposed to diethylstilbestrol in utero. Obstetrics and Gynecology, Vol.56, No.1, pp. 70-76.

Daeseleire, E.; Vanoosthuyze, K. \& Van Peteghem, C. (1994). Application of highperformance thin-layer chromatography and gas chromatography-mass spectrometry to the detection of new anabolic steroids used as growth promoters in cattle fattening. Journal of Chromatography A, Vol.674, No.1-2, pp. 247-253.

Daxenberger, A.; Ibarreta, D. \& Meyer, H. H. D. (2001). Possible health impact of animal oestrogens in food. Human Reproduction Update, Vol.7, No.3, pp. 340-355.

De Brabander, H. F.; Le Bizec, B.; Pinel, G.; Antignac, J.P.; Verheyden, K.; Mortier, V.; Courtheyn, D. \& Noppe, H. (2007). Past, present and future of mass spectrometry in the analysis of residues of banned substances in meat-producing animals. Journal of Mass Spectrometry, Vol.42, No.8, pp. 983-998.

Dervilly-Pinel, G.; Weigel, S.; Lommen, A.; Chereau, S.; Rambaud, L.; Essers, M.; Antignac, J.P.; Nielen, M.W.F. \& Le Bizec, B. (2011). Assessment of two complementary liquid chromatography coupled to high resolution mass spectrometry metabolomics strategies for the screening of anabolic steroid treatment in calves. Analytica Chimica Acta, Vol.700, No.1-2, pp. 144-154.

Dikeman, M. E. (2007). Effects of metabolic modifiers on carcass traits and meat quality. Meat Science, Vol.77, No.1, pp. 121-135.

Draisci, R.; Palleschi, L.; Ferretti, E.; Lucentini, L. \& Cammarata, P. (2000). Quantitation of anabolic hormones and their metabolites in bovine serum and urine by liquid chromatography-tandem mass spectrometry. Journal of Chromatography A, Vol.870, No.1-2, pp. 511-522.

Duffy, E.; Rambaud, L.; Le Bizec, B. \& O'Keeffe, M. (2009). Determination of hormonal growth promoters in bovine hair: Comparison of liquid chromatography-mass spectrometry and gas chromatography-mass spectrometry methods for estradiol benzoate and nortestosterone decanoate. Analytica Chimica Acta, Vol.637, No.1-2, pp. 165-172.

Duffy, E. F.; Danaher, M. \& O'Keeffe, M. (2008). Determination of steroid esters in bovine hair using LC-MS/MS. Proceedings of the EuroResidue VI (Conference on Residues of Veterinary Drugs in Food), Vol. 3, pp. 1025-1030.

Dunn, W. B.; Broadhurst, D.; Brown, M.; Baker, P. N.; Redman, C. W. G.; Kenny, L. C. \& Kell, D.B. (2008). Metabolic profiling of serum using ultra performance liquid chromatography and the LTQ-orbitrap mass spectrometry system. Journal of Chromatography B, Vol.871, No.2, pp. 288-298.

EEC (1988a). Directive 81/602/EEC. Official Journal of the European Communities, No.L222, pp. 32-33.

EEC (1988b). Directive 88/299/EEC. Official Journal of the European Communities, No.L128, pp. 36-38.

EC (1996a). Directive 96/22/EC. Official Journal of the European Communities, No.L125, pp. 3-9.

EC (1996b). Directive 96/23/EC. Official Journal of the European Communities, No.L125, pp. 10-32.

EC (2002). Decision 2002/657/EC. Official Journal of the European Union, No.L221, pp. 8-36.

EC (2003). Directive 2003/74/EC. Official Journal of the European Union, No.L262, pp. 17-21. 
EC (2008). Directive 2008/97/EC. Official Journal of the European Union, No.L318, pp. 9-11.

Eriksson, L.; Antti, H.; Gottfries, J.; Holmes, H.; Johansson, E.; Lindgren, F.; Long, I.; Lundstedt, T.; Trygg, J. \& Wold, S. (2004). Using chemometrics for navigating in the large data sets of genomics, proteomics and metabolomics (gpm). Analytical and Bioanalytical Chemistry, Vol.380, pp. 419-429.

European Commission, Directorate General for Health \& Consumers (2004). SANCO/2004/2726rev1: Guidelines for the implementation of Decision 2002/657/EC.

Farlow, D. W.; Xu, X. \& Veenstra, T. D. (2009). Quantitative measurement of endogenous estrogen metabolites, risk-factors for developement of breast cancer, in commercial milk products by LC-MS/MS. Journal of Chromatography B, Vol.877, pp. 1327-1334.

Ferchaud, V.; Le Bizec, B.; Monteau, F. \& Andre, F. (2000). Characterization of exogenous testosterone in livestock by gas chromatography/combustion/isotope ratio mass spectrometry: Influence of feeding and age. Rapid Communications in Mass Spectrometry, Vol.14, No.8, pp. 652-656.

Foster, P. A.; Chander, S. K.; Parsons, M. F. C.; Newman, S. P.; Woo, L. W. L.; Potter, B. V. L.; Reed, M.J. \& Purohit, A. (2008). Efficacy of three potent steroid sulfatase inhibitors: Pre-clinical investigations for their use in the treatment of hormone-dependent breast cancer. Breast Cancer Research and Treatment, Vol.111, No.1, pp. 129-138.

Fritsche, S.; Rumsey, T.; Meyer, H.; Schmidt, G. \& Steinhart, H. (1999). Profiles of steroid hormones in beef from steers implanted with synovex-S (estradiol benzoate and progesterone) in comparison to control steers. Zeitschrift Für Lebensmitteluntersuchung Und -Forschung A, Vol.208, No.5-6, pp. 328-331.

Ganmaa, D., Cui, X., Feskanich, D., Hankinson, S. E., \& Willett, W. C. (2011). Milk, dairy intake and risk of endometrial cancer: A twenty six-year follow-up. International Journal of Cancer, (DOI: 10.1002/ijc.26265).

Ganmaa, D. \& Sato, A. (2005). The possible role of female sex hormones in milk from pregnant cows in the development of breast, ovarian and corpus uteri cancers. Medical Hypotheses, Vol.65, No.6, pp. 1028-1037.

Ganmaa, D.; Wang, P. Y.; Qin, L. Q.; Hoshi, K. \& Sato, A. (2001). Is milk responsible for male reproductive disorders? Medical Hypotheses, Vol.57, No.4, pp. 510-514.

Garner, B.; Phassouliotis, C.; Phillips, L. J.; Markulev, C.; Butselaar, F.; Bendall, S.; Yung, Y. \& McGorry, P.D. (2011). Cortisol and dehydroepiandrosterone-sulphate levels correlate with symptom severity in first-episode psychosis. Journal of Psychiatric Research, Vol.45, No.2, pp. 249-255.

Givens, D. I.; Morgan, R. \& Elwood, P. C. (2008). Relationship between milk consumption and prostate cancer: A short review. Nutrition Bulletin, Vol.33, pp. 279-286.

Gratacós-Cubarsí, M.; Castellari, M.; Valero, A. \& García-Regueiro, J. A. (2006). Hair analysis for veterinary drug monitoring in livestock production. Journal of Chromatography $B$, Vol.834, No.1-2, pp. 14-25.

Haney, A. F. \& Hammond, M. G. (1983). Infertility in women exposed to diethylstilbestrol in utero. Journal of Reproductive Medicine for the Obstetrician and Gynecologist, Vol.28, No.12, pp. 851-856.

Hartmann, S.; Lacorn, M. \& Steinhart, H. (1998). Natural occurrence of steroid hormones in food. Food Chemistry, Vol.62, No.1, pp. 7-20.

Hebestreit, M.; Flenker, U. ; Buisson, C.; Andre, F.; Le Bizec, B.; Fry, H.; Lang, M.; Weigert, A.P.; Heinrich, K.; Hird, S. \& Schanzer, W. (2006). Application of stable carbon 
isotope analysis to the detection of testosterone administration to cattle. Journal of Agricultural and Food Chemistry, Vol.54, No.8, pp. 2850-2858.

Herman-Giddens, M. E.; Slora, E. J.; Wasserman, R. C.; Bourdony, C. J.; Bhapkar, M. V.; Koch, G. G. \& Hasemeier, C.M. (1997). Secondary sexual characteristics and menses in young girls seen in office practice: A study from the pediatric research in office settings network. Pediatrics, Vol.99, No.4, pp. 505-512.

Hooijerink, H.; Lommen, A.; Mulder, P. P. J.; Van Rhijn, J. A. \& Nielen, M. W. F. (2005). Liquid chromatography-electrospray ionisation-mass spectrometry based method for the determination of estradiol benzoate in hair of cattle. Analytica Chimica Acta, Vol.529, (1-2 SPEC. ISS.), pp. 167-172.

Hunter R.A. (2010). Hormonal growth promotant use in the australian beef industry. Animal Production Science, Vol.50, pp. 637-659.

Huyghe, E.; Matsuda, T. \& Thonneau, P. (2003). Increasing incidence of testicular cancer worldwide: A review. Journal of Urology, Vol.170; No.1, pp. 5-11.

Igo, J. L.; Brooks, J. C.; Johnson, B. J.; Starkey, J.; Rathmann, R. J.; Garmyn, A. J.; Nichols, W.T.; Hutcheson, J.P. \& Miller, M.F. (2011). Characterization of estrogen-trenbolone acetate implants on tenderness and consumer acceptability of beef under the effect of 2 aging times. Journal of Animal Science, Vol.89, No.3, pp. 792-797.

Kaaks, R.; Rinaldi, S.; Key, T. J.; Berrino, F.; Peeters, P. H. M.; Biessy, C. et al. (2005). Postmenopausal serum androgens, oestrogens and breast cancer risk: The european prospective investigation into cancer and nutrition. Endocrine-Related Cancer, 12(4), 1071-1082.

Kaklamanos, G.; Theodoridis, G.; Papadoyannis, I. N. \& Dabalis, T. (2007). Determination of anabolic steroids in muscle tissue by liquid chromatography-tandem mass spectrometry. Journal of Agricultural and Food Chemistry, Vol.55, No.21, pp. 83258330.

Kaklamanos, G.; Theodoridis, G. A.; Dabalis, T. \& Papadoyannis, I. (2011). Determination of anabolic steroids in bovine serum by liquid chromatography-tandem mass spectrometry. Journal of Chromatography B, Vol.879, No.2, pp. 225-229.

Kaklamanos, G.; Theodoridis, G. \& Dabalis, T. (2009a). Determination of anabolic steroids in bovine urine by liquid chromatography-tandem mass spectrometry. Journal of Chromatography B, Vol.877, No.23, pp. 2330-2336.

Kaklamanos, G.; Theodoridis, G. \& Dabalis, T. (2009b). Gel permeation chromatography clean-up for the determination of gestagens in kidney fat by liquid chromatography-tandem mass spectrometry and validation according to 2002/657/EC. Journal of Chromatography A, Vol.1216, No.46, pp. 8067-8071.

Kieken, F.; Pinel, G.; Antignac, J.P.; Paris, A.; Garcia, P.; Popot, M. G.; Grall, M.; Mercadier, V.; Toutain, P.L. ; Bonnaire, Y. \& Le Bizec, B. (2011). Generation and processing of urinary and plasmatic metabolomic fingerprints to reveal an illegal administration of recombinant equine growth hormone from LC-HRMS measurements. Metabolomics, Vol.7, No.1, pp. 84-93.

Kushnir, M. M.; Blamires, T.; Rockwood, A. L.; Roberts, W. L.; Yue, B.; Erdogan, E.; Bunker, A.M. \& Meikle, A.W. (2010). Liquid chromatography-tandem mass spectrometry assay for androstenedione, dehydroepiandrosterone, and testosterone with pediatric and adult reference intervals. Clinical Chemistry, Vol.56, No.7, pp. 11381147. 
Kvarnryd, M.; Grabic, R.; Brandt, I. \& Berg, C. (2011). Early life progestin exposure causes arrested oocyte development, oviductal agenesis and sterility in adult xenopus tropicalis frogs. Aquatic Toxicology, Vol.103, No.1-2, pp.18-24.

Lane, E. A.; Austin, E. J. \& Crowe, M. A. (2008). Oestrous synchronisation in cattle-current options following the EU regulations restricting use of oestrogenic compounds in food-producing animals: A review. Animal Reproduction Science, Vol.109, No.1-4, pp. 1-16.

Le Bizec, B.; Pinel, G. \& Antignac, J. (2009). Options for veterinary drug analysis using mass spectrometry. Journal of Chromatography A, Vol.1216. No.46, pp. 8016-8034.

Lee, C. Y.; Lee, H. P.; Jeong, J. H.; Baik, K. H.; Jin, S. K.L; Lee, J. H. \& Sohnt, S.H. (2002). Effects of restricted feeding, low-energy diet, and implantation of trenbolone acetate plus estradiol on growth, carcass traits, and circulating concentrations of insulin-like growth factor (IGF)-I and IGF-binding protein-3 in finishing barrows. Journal of Animal Science, Vol.80, No.1, pp. 84-93.

Levy, L. S. (2010). CHAPTER 1 . The use of hormomally active substances in veterinary and zootechnical uses - the continuing scientific and regulatory challenges. In : Analyses for hormonal substances in food-producing animals, J.F. Kay (Ed.), The Royal Society of Chemistry.

Lindon, J. C.; Holmes, E.; Bollard, M. E.; Stanley, E. G. \& Nicholson, J. K. (2004). Metabonomics technologies and their applications in physiological monitoring, drug safety assessment and disease diagnosis. Biomarkers, Vol.9, No.1, pp. 1-31.

Loizzo, A. (1984). The case of diethylstilbestrol treated veal contained in homogenized babyfoods in italy. Methodological and toxicological aspects. Annali Dell'Istituto Superiori Di Sanità, Vol.20, No.2-3, pp. 215.

Loizzo, A.; Gatti, G. L.; Macri, A.; Moretti, G.; Ortolani, E. \& Palazzesi, S. (1984). Italian baby food containing diethylstilbestrol - 3 years later. Lancet, Vol.1, No.8384, pp. 10141015.

Lukanova, A.; Lundin, E.; Micheli, A.; Arslan, A.; Ferrari, P.; Rinaldi, S.; Krogh, V.; Lenner, P.; Shore, R.E.; Biessy, C.; Muti, P.; Riboli, E.; Koenig, K.; Levitz, M.; Stattin, P.; Berrino, F.; Hallmans, G.; Kaaks, R.; Toniolo, P. \& Zeleniuch-Jacquotte, A. (2004). Circulating levels of sex steroid hormones and risk of endometrial cancer in postmenopausal women. International Journal of Cancer, Vol.108, No.3, pp. 425-432.

Lusk, J. L. \& Fox, J. A. (2002). Consumer demand for mandatory labeling of beef from cattle administered growth hormones or fed genetically modified corn. Journal of Agricultural and Applied Economics, Vol.34, No.1, pp. 27-38.

Lutz, U. ; Lutz, R. W. \& Lutz, W. K. (2006). Metabolic profiling of glucuronides in human urine by LC-MS/MS and partial least-squares discriminant analysis for classification and prediction of gender. Analytical Chemistry, Vol.78, No.13, pp. 4564-4571.

Martínez, M. F.; Kastelic, J. P.; Adams, G. P.; Cook, B.; Olson, W. O. \& Mapletoft, R. J. (2002). The use of progestins in regimens for fixed-time artificial insemination in beef cattle. Theriogenology, Vol.57, No.3, pp. 1049-1059.

Maruyama, K.; Oshima, T. \& Ohyama, K. (2010). Exposure to exogenous estrogen through intake of commercial milk produced from pregnant cows. Pediatrics International, Vol.52, No.1, pp. 33-38. 
Maume, D.; Deceuninck, Y.; Pouponneau, K.; Paris, A.; Le Bizec, B. \& André, F. (2001). Assessment of estradiol and its metabolites in meat. Acta Pathologica, Microbiologica et Immunologica Scandinavica, Vol.109, No.1, pp. 32-38.

Maume, D.; Le Bizec, B.; Pouponneau, K.; Deceuninck, Y.; Solere, V.; Paris, A.; Antignac, J.P. \& André, F. (2003). Modification of $17 \beta$-estradiol metabolite profile in steer edible tissues after estradiol implant adminsitration. Analytica Chimica Acta, Vol.483, pp. 289-297.

McPhee, M. J.; Oltjen, J. W.; Famula, T. R. \& Sainz, R. D. (2006). Meta-analysis of factors affecting carcass characteristics of feedlot steers. Journal of Animal Science, Vol.84, pp. 3143-3154.

Meireles, S. I.; Esteves, G. H.; Hirata, R.; Peri, S.; Devarajan, K.; Slifker, M.; Mosier, S.L.; Peng, J.; Vadhanam, M.V.; Hurst, H.E.; Neves, E.J.; Reis, L.F.; Gairola, C.G.; Gupta, R.C. \& Clapper, M.L. (2010). Early changes in gene expression induced by tobacco smoke: Evidence for the importance of estrogen within lung tissue. Cancer Prevention Research, Vol.3, No.6, pp. 707-717.

Melnik, B. C. (2009). Milk - the promoter of chronic western diseases. Medical Hypotheses, Vol.72, No.6, pp. 631-639.

Micheli, A.; Muti, P. ; Secreto, G.; Krogh, V.; Meneghini, E.; Venturelli, E.; Sieri, S.; Pala, V. \& Berrino, F. (2004). Endogenous sex hormones and subsequent breast cancer in premenopausal women. International Journal of Cancer, Vol.112, No.2, pp. 312-318.

Moal, V.; Mathieu, E.; Reynier, P.; Malthièry, Y. \& Gallois, Y. (2007). Low serum testosterone assayed by liquid chromatography-tandem mass spectrometry. Comparison with five immunoassay techniques. Clinica Chimica Acta, Vol.386, No.1-2, pp. 12-19.

Mooney, M. H.; Elliott, C. T. \& Le Bizec, B. (2009). Combining biomarker screening and mass-spectrometric analysis to detect hormone abuse in cattle. Trends in Analytical Chemistry, Vol.28, No.6, pp. 665-675.

Mooney, M. H.; Situ, C.; Cacciatore, G.; Hutchinson, T.; Elliott, C. \& Bergwerff, A. A. (2008). Plasma biomarker profiling in the detection of growth promoter use in calves. Biomarkers, Vol.13, No.3, pp. 246-256.

Nelson, R. E.; Grebe, S. K.; O'Kane, D. J. \& Singh, R. J. (2004). Liquid chromatography tandem mass spectrometry assay for simultaneous measurement of estradiol and estrone in human plasma. Clinical Chemistry, Vol.50, No.2, pp. 373-384.

Noppe, H.; Le Bizec, B.; Verheyden, K. \& De Brabander, H. F. (2008). Novel analytical methods for the determination of steroid hormones in edible matrices. Analytica Chimica Acta, Vol.611, No.1, pp. 1-16.

Pape-Zambito, D. A.; Roberts, R. F. \& Kensinger, R. S. (2010). Estrone and 17 $\beta$-estradiol concentrations in pasteurized-homogenized milk and commercial dairy products. Journal of Dairy Science, Vol.93, No.6, pp. 2533-2540.

Parent, A.; Teilmann, G.; Juul, A.; Skakkebaek, N. E.; Toppari, J. \& Bourguignon, J. (2003). The timing of normal puberty and the age limits of sexual precocity: Variations around the world, secular trends, and changes after migration. Endocrine Reviews, Vol.24, No.5, pp. 668-693.

Parr, S. L.; Chung, K. Y.; Hutcheson, J. P.; Nichols, W. T.; Yates, D. A.; Streeter, M. N.; Swingle, R.S.; Galyean, M.L. \& Johnson, B.J. (2011). Dose and release pattern of anabolic implants affects growth of finishing beef steers across days on feed. Journal of Animal Science, Vol.89, No.3, pp. 863-873. 
Partsch, C. \& Sippell, W. G. (2001). Pathogenesis and epidemiology of precocious puberty. effects of exogenous oestrogens. Human Reproduction Update, Vol.7, No.3, pp. 292302.

Pedreira, S.; Lolo, M.; Vázquez, B. I.; Franco, C. M.; Cepeda, A. \& Fente, C. (2007). Liquid chromatography-electrospray ionization-mass spectrometry method in multiple reaction monitoring mode to determine 17a-ethynylestradiol residues in cattle hair without previous digestion. Journal of Agricultural and Food Chemistry, Vol.55, No.23, pp. 9325-9329.

Pinel, G.; Weigel, S.; Antignac, J.P.; Mooney, M. H.; Elliott, C.; Nielen, M. W. F. \& Le Bizec, B. (2010). Targeted and untargeted profiling of biological fluids to screen for anabolic practices in cattle. Trends in Analytical Chemistry, Vol.29, No.11, pp. 12691280 .

Pleadin, J.; Terzić, S.; Perši, N. \& Vulić, A. (2011). Evaluation of steroid hormones anabolic use in cattle in croatia. Biotechnology in Animal Husbandry, Vol.7, No.2, pp. 7-2.

Poelmans, S.; De Wasch, K.; Noppe, H.; Van Hoof, N.; Van Cruchten, S.; Le Bizec, B.; Deceuninck, Y.; Sterk, S.; Van Rossum, H.J.; Hoffman, M.K. \& De Brabander, H.F. (2005a). Endogenous occurrence of some anabolic steroids in swine matrices. Food Additives and Contaminants, Vol.22, No.9, pp. 808-815.

Poelmans, S.; De Wasch, K.; Noppe, H.; Van Hoof, N.; Van De Wiele, M.; Courtheyn, D.; Gillis, W.; Vanthemsche, P.; Janssen, C.R. \& De Brabander, H.F. (2005b). Androstadienetrione, a boldenone-like component, detected in cattle faeces with GC-MSn and LC-MSn. Food Additives and Contaminants, Vol.22, No.9, pp. 798-807.

Pohjanen, E.; Thysell, E.; Jonsson, P.; Eklund, C.; Silfver, A.; Carlsson, I.B.; Lundgren, K.; Moritz, T.; Svensson, M.B. \& Antti, H. (2007). A multivariate screening strategy for investigating metabolic effects of strenuous physical exercise in human serum. Jounal of Proteome Research, Vol.6, No.6, pp. 2113-2120.

Prins, G. S. (2008). Endocrine disruptors and prostate cancer risk. Endocrine-Related Cancer, Vol.15, No.3, pp. 649-656.

Rambaud, L.; Bichon, E.; Cesbron, N.; André, F. \& Le Bizec, B. (2005). Study of 17 $\beta$-estradiol3-benzoate, 17a-methyltestosterone and medroxyprogesterone acetate fixation in bovine hair. Analytica Chimica Acta, Vol.532, No.2, pp. 165-176.

Regal, P.; Vázquez, B. I.; Franco, C. M.; Cepeda, A. \& Fente, C. A. (2008). Development of a rapid and confirmatory procedure to detect $17 \beta$-estradiol 3-benzoate treatments in bovine hair. Journal of Agricultural and Food Chemistry, Vol.56, No.24, pp. 1160711611.

Riedmaier, I.; Becker, C.; Pfaffl, M. W. \& Meyer, H. H. D. (2009). The use of omic technologies for biomarker development to trace functions of anabolic agents. Journal of Chromatography A, Vol.1216, pp. 8192-8199.

Rijk, J. C. W.; Lommen, A.; Essers, M. L.; Groot, M. J.; Van Hende, J. M.; Doeswijk, T. G. \& Nielen, M.W.F. (2009). Metabolomics approach to anabolic steroid urine profiling of bovines treated with prohormones. Analytical Chemistry, Vol.81, No.16, pp. 68796888.

Rosenfeld, D. L. \& Bronson, R. A. (1980). Reproductive problems in the DES-exposed female. Obstetrics and Gynecology, Vol.55, No.4, pp. 453-456.

Salman, M.; New, J. C. J.; Bailey, M.; Brown, C.; Detwiler, L.; Galligan, D.; Hall, C.; Kennedy, M.; Lonergan, G.; Mann, L.; Renter, D.; Saeed, M.; White, B. \& Zika, S. (2008). 
Global food systems and public health: Production methods and animal husbandry, A national commission on industrial farm animal production report. pew commission on industrial farm animal production. In: Comparative Medicine Publications and Other Works, 01.09.2011, Available from http://trace.tennessee.edu/utk_compmedpubs/32

Scheffler, J. M.; Buskirk, D. D.; Rust, S. R.; Cowley, J. D. \& Doumit, M. E. (2003). Effect of repeated administration of combination trenbolone acetate and estradiol implants on growth, carcass traits, and beef quality of long-fed holstein steers. Journal of Animal Science, Vol.81, pp. 2395-2400.

Scheltema, R. A.; Kamleh, A.; Wildridge, D.; Ebikeme, C.; Watson, D. G.; Barrett, M. R.; Jansen, R.C. \& Breitling, R. (2008). Increasing the mass accuracy of high-resolution LC-MS data using background ions - a case study on the LTQ-orbitrap. Proteomics, Vol.8, No.22, pp. 4647-4656.

Scippo, M.; Degand, G.; Duyckaerts, A.; Maghuin-Rogister, G. \& Delahaut, P. (1994). Control of the illegal administration of natural steroid hormones in the plasma of bulls and heifers. Analyst, Vol.119, No.12, pp. 2639-2644.

Senger, P. L. (1994). The estrus detection problem: New concepts, technologies, and possibilities Journal of Dairy Science, Vol.77, No.9, pp. 2745-2753.

Shao, B.; Zhao, R.; Meng, J.; Xue, Y.; Wu, G.; Hu, J. \& Tu, X. (2005). Simultaneous determination of residual hormonal chemicals in meat, kidney, liver tissues and milk by liquid chromatography-tandem mass spectrometry. Analytica Chimica Acta, Vol.548, No.1-2, pp. 41-50.

Shatalova, E. G.; Klein-Szanto, A. J. P.; Devarajan, K.; Cukierman, E. \& Clapper, M. L. (2011). Estrogen and cytochrome P450 1B1 contribute to both early- and late-stage head and neck carcinogenesis. Cancer Prevention Research, Vol.4, No.1, pp. 107-115.

Sheridan, P. J.; Austin, F. H.; Bourke, S. \& Roche, J. F. (1990). The effect of anabolic agents on growth rate and reproductive organs of pigs. Livestock Production Science, Vol.26, No.4, pp. 263-275.

Simontacchi, C.; Perez De Altamirano, T.; Marinelli, L.; Angeletti, R. \& Gabai, G. (2004). Plasma steroid variations in bull calves repeatedly treated with testosterone, nortestosterone and oestradiol administered alone or in combination. Veterinary Research Communications, Vol.28, No.6, pp. 467-477.

Sorwell, K. G. \& Urbanski, H. F. (2010). Dehydroepiandrosterone and age-related cognitive decline. Age, Vol.32, No.1, pp. 61-67.

Sottas, P.; Saudan, C.; Schweizer, C.; Baume, N.; Mangin, P. \& Saugy, M. (2008). From population- to subject-based limits of $\mathrm{T} / \mathrm{E}$ ratio to detect testosterone abuse in elite sports. Forensic Science International, Vol.174, No.2-3, pp. 166-172.

Stanczyk, F. Z.; Lee, J. S. \& Santen, R. J. (2007). Standardization of steroid hormone assays: Why, how, and when? Cancer Epidemiology Biomarkers and Prevention, Vol.16, No.9, pp. 1713-1719.

Stephany, R. (2001). Hormones in meat: Different approaches in the EU and in the USA. Acta Pathologica, Microbiologica et Immunologica Scandinavica, Vol.109, pp. S357-S363

Stolker, A.; Groot, M.; Lasaroms, J.; Nijrolder, A.; Blokland, M. \& Riedmaier, I. (2009). Detectability of testosterone esters and estradiol benzoate in bovine hair and plasma following pour-on treatment. Analytical and Bioanalytical Chemistry, Vol.395, No.4, pp. 1075-1087. 
Stolker, A. A. M.; Rutgers, P.; Oosterink, E.; Lasaroms, J. J. P.; Peters, R. J. B.; Van Rhijn, J. A. \& Nielen, M.W.F. (2008). Comprehensive screening and quantification of veterinary drugs in milk using UPLC-ToF-MS. Analytical and Bioanalytical Chemistry, Vol.391, No.6, pp. 2309-2322.

Strahm, E.; Baume, N.; Mangin, P.; Saugy, M.; Ayotte, C. \& Saudan, C. (2009). Profiling of 19-norandrosterone sulfate and glucuronide in human urine: Implications in athlete's drug testing. Steroids, Vol.74, No.3, pp. 359-364.

Strous, R. D.; Maayan, R.; Lapidus, R.; Goredetsky, L.; Zeldich, E.; Kotler, M. \& Weizman, A. (2004). Increased circulatory dehydroepiandrosterone and dehydroepiandrosterone sulphate in first-episode schizophrenia: Relationship to gender, aggression and symptomatology. Schizophrenia Research, Vol.71, No.2-3, pp. 427-434.

Swan, S. H.; Liu, F.; Overstreet, J. W.; Brazil, C. \& Skakkebaek, N. E. (2007). Semen quality of fertile US males in relation to their mothers' beef consumption during pregnancy. Human Reproduction, Vol.22, No.6, pp. 1497-1502.

Torrado, S.; Roig, M.; Farré, M.; Segura, J. \& Ventura, R. (2008). Urinary metabolic profile of 19-norsteroids in humans: Glucuronide and sulphate conjugates after oral administration of 19-nor-4-androstenediol. Rapid Communications in Mass Spectrometry, Vol.22, No.19, pp. 3035-3042.

U.S. Department of Health and Human Services (FDA) (2006). Guidance for industry: General principles for evaluating the safety of compounds used in food-producing animals.

U.S. FDA (2010). Animal drugs @ FDA. 13/07/2010, Available from http://www.accessdata.fda.gov/scripts/animaldrugsatfda/index.cfm

USDA (2009). Beef 2007-08, part III: Changes in the U.S. beef cow-calf industry, 1993-2008. In: USDA:APHIS:VS, CEAH. Fort Collins, CO(\#N512-1008)

Vallejo, M.; Garcia, A.; Tunon, J.; García-Martínez, D.; Angulo, S.; Martín-Ventura, J. L.; Blanco-Colio, L.M.; Almeida, P.; Egido, J. \& Barbas, C. (2009). Plasma fingerprinting with GC-MS in acute coronary syndrome. Analytical and Bioanalytical Chemistry, Vol.394, No.6, pp. 1517-1524.

Vanhaecke, L.; Bussche, J. V.; Wille, K.; Bekaert, K. \& De Brabander, H. F. (2011). Ultra-high performance liquid chromatography-tandem mass spectrometry in highthroughput confirmation and quantification of 34 anabolic steroids in bovine muscle. Analytica Chimica Acta, Vol.700, No.1-2, pp. 70-77.

Vilariño, M.; Rubianes, E.; van Lier, E. \& Menchaca, A. (2010). Serum progesterone concentrations, follicular development and time of ovulation using a new progesterone releasing device (DICO $\left.{ }^{\circledR}\right)$ in sheep. Small Ruminant Research, Vol.91, No.2-3, pp. 219-224.

Wang, Y.; Tang, H.; Nicholson, J. K.; Hylands, P. J.; Sampson, J. \& Holmes, E. (2005). A metabolic strategy for the detection of the metabolic effects of chamomile (matricaria recutita L.) ingestion. Journal of Agricultural and Food Chemistry, Vol.53, pp. 191-196.

Werner, E.; Croixmarie, V.; Umbdenstock, T.; Ezan, E.; Chaminade, P.; Tabet, J. C. \& Junot, C. (2008). Mass spectrometry-based metabolomics: Accelerating the characterization of discriminating signals by combining statistical correlations and ultrahigh resolution. Analytical Chemistry, Vol.80, No.13, pp. 4918-4932. 
Wigle, D. T.; Turner, M. C.; Gomes, J. \& Parent, M. (2008). Role of hormonal and other factors in human prostate cancer. Journal of Toxicology and Environmental Health Part B: Critical Reviews, Vol.11, No.3-4, pp. 242-259.

Wiley, A. S. (2011). Milk intake and total dairy consumption: Associations with early menarche in NHANES 1999-2004. PLoS ONE, Vol.6, No.2, pp. e14685.

Xu, C. L.; Chu, X. G.; Peng, C. F.; Jin, Z. Y. \& Wang, L. Y. (2006). Development of a faster determination of 10 anabolic steroids residues in animal muscle tissues by liquid chromatography tandem mass spectrometry. Journal of Pharmaceutical and Biomedical Analysis, Vol.41, No.12, pp. 616-621.

Yager, J. D. \& Davidson, N. E. (2006). Estrogen carcinogenesis in breast cancer. New England Journal of Medicine, Vol.354, No.3, pp. 270-282.

Yang, Y.; Shao, B.; Zhang, J.; Wu, Y. \& Duan, H. (2009). Determination of the residues of 50 anabolic hormones in muscle, milk and liver by very-high-pressure liquid chromatography-electrospray ionization tandem mass spectrometry. Journal of Chromatography B, Vol.877, pp. 489-496.

Zhong, S.; Ye, W.; Feng, E.; Lin, S.; Liu, J.; Leong, J.; Ma, C. \& Lin, Y.C. (2011). Serum derived from zeranol-implanted ACI rats promotes the growth of human breast cancer cells in vitro. Anticancer Research, Vol.31, No.2, pp. 481-486. 


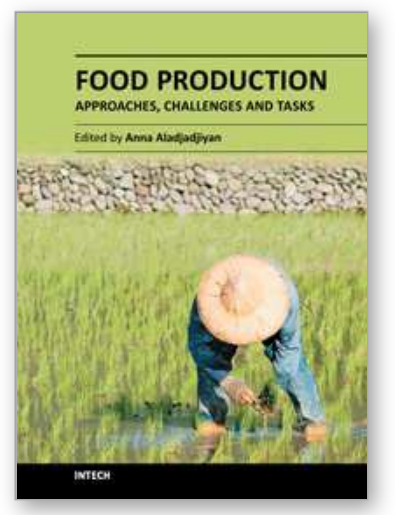

\author{
Food Production - Approaches, Challenges and Tasks \\ Edited by Prof. Anna Aladjadjiyan
}

ISBN 978-953-307-887-8

Hard cover, 270 pages

Publisher InTech

Published online 20, January, 2012

Published in print edition January, 2012

This book is devoted to food production and the problems associated with the satisfaction of food needs in different parts of the world. The emerging food crisis calls for development of sustainable food production, and the quality and safety of the food produced should be guaranteed. The book contains thirteen chapters and is divided into two sections. The first section is related to social issues rising from food insufficiency in the third world countries, and is titled "Sustainable food production: Case studies". The case studies of semi-arid Africa, Caribbean and Jamaica, Burkina Faso, Nigeria, Pacific Islands, Mexico and Brazil are discussed. The second section, titled "Scientific Methods for Improving Food Quality and Safety", covers the methods for control and avoidance of food contaminants. Substitution of chemical treatment with physical, rapid analytical methods for control of contaminants, problems in animal husbandry related to diary production and hormones in food producing animals, approaches and tasks in maize and rice production are in the covered by 6 chapters in this section.

\title{
How to reference
}

In order to correctly reference this scholarly work, feel free to copy and paste the following:

atricia Regal, Alberto Cepeda and Cristina A. Fente (2012). Natural Hormones in Food-Producing Animals:Legal Measurements and Analytical Implications, Food Production - Approaches, Challenges and Tasks, Prof. Anna Aladjadjiyan (Ed.), ISBN: 978-953-307-887-8, InTech, Available from: http://www.intechopen.com/books/food-production-approaches-challenges-and-tasks/natural-hormones-infood-producing-animals-legal-measurements-and-analytical-implications

\section{INTECH}

open science | open minds

\section{InTech Europe}

University Campus STeP Ri

Slavka Krautzeka 83/A

51000 Rijeka, Croatia

Phone: +385 (51) 770447

Fax: +385 (51) 686166

www.intechopen.com

\section{InTech China}

Unit 405, Office Block, Hotel Equatorial Shanghai

No.65, Yan An Road (West), Shanghai, 200040, China 中国上海市延安西路65号上海国际贵都大饭店办公楼405单元

Phone: +86-21-62489820

Fax: $+86-21-62489821$ 
(C) 2012 The Author(s). Licensee IntechOpen. This is an open access article distributed under the terms of the Creative Commons Attribution 3.0 License, which permits unrestricted use, distribution, and reproduction in any medium, provided the original work is properly cited. 